\title{
Formas de tratamento e construção da relação interpessoal em Contos da Montanha de Miguel Torga
}

\author{
Maria Aldina Marques \\ ILCH - Universidade do Minho
}

Studies in the pragmatics of language use have shown that defining and maintaining relationships is one of the most important functions of speech.

(Parkinson, 1985: 3)

\begin{abstract}
Resumo:
As relações interpessoais, criadas em cada interacção verbal constituem uma dimensão fundamental da construção discursiva. Em Contos da Montanha, Miguel Torga retrata/ cria uma sociedade rural cujo traço dominante e primeiro parece ser o da solidariedade. Mas a estrutura social só aparentemente é simples. As formas de tratamento, em particular, mostram a especificidade das relações interpessoais, que irei analisar, de acordo com os eixos de distância, poder e conflito, que propõe Catherine Kerbrat-Orecchioni (1992) na sequência de Brown e Levinson (1987).
\end{abstract}

\section{Palavras-chave:}

Análise do discurso, discurso literário, formas de tratamento, relações interpessoais, teoria da cortesia.

\begin{abstract}
:
Interpersonal relations, created in every verbal interaction, constitute a fundamental dimension of the discursive construction. In Contos da Montanha, Miguel Torga portrays/ creates a rural society in which solidarity seems to be first and foremost the dominant feature. But the social structure is only apparently simple. Forms of address, in particular, show the specificity of interpersonal relations which I shall examine paying attention to the parameters of distance, power and conflict proposed by Catherine Kerbrat-Orecchioni (1992) after Brown and Levinson (1987).
\end{abstract}

Key words:

Discourse analysis, literary discourse, forms of address, interpersonal relations, courtesy theory. 


\section{Análise Linguística do Discurso e Discurso Literário}

A análise do discurso tem como objecto os discursos na sua heterogeneidade e especificidade. Assumindo uma perspectiva pragmática da linguagem em uso, esta abordagem teórica presta a mesma atenção investigativa a qualquer discurso, sem valorizar uns sobre outros, sem esquecer uns por outros. Neste enquadramento teórico-metodológico se coloca a análise linguística do género "discurso literário". Desde logo, sobressaem as potencialidades linguísticas de um género que se caracteriza, em termos linguísticos, pela criatividade. Aqui, o uso da língua atinge níveis de realização máximos. Cabe agora, pois, desfazer um equívoco: o interesse pelos discursos, por todos os géneros de discurso não diminui em nada o interesse científico pelo discurso literário. A Análise do Discurso, as Ciências da Linguagem, ou a Linguística no seu sentido mais amplo, ficariam limitadas no seu objecto e na sua investigação se afastassem do seu campo de análise o discurso literário. Ocasionais polémicas e contestações dos interesses científicos da análise do discurso não passam de um receio infundado, criado por um irresponsável exagero quando, ao contrário da Gramática Tradicional, as novas perspectivas de análise linguística alargaram o campo de análise a todos os géneros discursivos, na atenção global à linguagem em uso.

\section{Corpus: apresentação e descrição. Questões teórico-metodológicas}

Restringi a análise à obra Contos da Montanha, de Miguel Torga. É um conjunto de 23 contos, sobre o quotidiano de pequenas aldeias transmontanas. Esta obra foi publicada pela primeira vez em 1941, com o título Montanha, mas entretanto apreendida pela PVDE, e publicada no Brasil, em 1955, como Contos da Montanha. Só em 1968 foi novamente editada em Portugal ${ }^{1}$. Os exemplos e remissões aqui apresentados dizem respeito à $7^{\mathrm{a}}$ edição, de 1987 .

De cada conto, seleccionei para análise apenas os excertos de diálogo que aí ocorrem. Para além da importância na estrutura dos contos, os diálogos são a modalidade primeira do uso da linguagem verbal que, assim, é intrinsecamente dialógica ${ }^{2}$.

1 Miguel Torga, falecido em 17 de Janeiro de 1995, aos 87 anos de idade, foi um dos grandes escritores portugueses do século XX, conhecido sobretudo pela sua poesia, diários e contos.

2 Se a língua pressupõe ou melhor impõe sempre o Outro, o interlocutor, pode fazê-lo na modalidade do monólogo e/ou do diálogo, não deixa por isso de ser dialógica. De "falar é agir" proposto pelos filósofos da linguagem Austin e Searle a "falar é interagir" no que Bakhtine e mais tarde Benveniste, inter alia, propõem, se mostra a importância teórica deste conceito para a análise do discurso, em sentido amplo. 
A pragmática linguística como perspectiva de análise teórica enfatiza esta dimensão. Com efeito, trata-se de um dialogismo que conforma o próprio sistema linguístico, incompletamente analisado e entendido, se desligado do seu uso como propõem as teorias linguísticas da frase $\mathrm{e}^{3}$.

No discurso literário, o estudo dos diálogos levanta a questão teórico-metodológica da ficcionalidade dos diálogos face a situações reais, ou do quotidiano, de interacção verbal. São situações/objectos obviamente diversos, mas é possível, apesar dessa diversidade, convocar para analisar os diálogos ficcionais todo o dispositivo teórico-metodológico desenvolvido para a análise das interacções vebais. Ou seja, os princípios e conceitos teóricos desenvolvidos no âmbito da análise linguística do discurso $^{4}$ são aplicáveis, de pleno direito, ao Discurso Literário. Esta é uma questão importante que retoma a problemática da possibilidade/pertinência de uma análise linguística do discurso literário. Mas a especificidade deste não é mais do que a especificidade do género, um conceito central para a análise da heterogeneidade dos discursos, tão fulcral que justifica a opção por uma linguística dos géneros ${ }^{5}$. Do confronto de diferentes usos em diferentes situações e com objectivos também diversos advém a possibilidade de compreender a heterogeneidade da língua, do seu funcionamento e uso. Mas o reconhecimento da especificidade do discurso literário e do conto, em particular, obriga, por exemplo, à consideração da figura do narrador.

\subsection{Objectivo do estudo}

Não tenho como objectivo de estudo a estrutura dialogal, característica da análise conversacional de uma primeira fase, mas antes -e apenas- o uso das formas de tratamento, que mostram no discurso o tipo de relação interpessoal existente ${ }^{6}$. A partir destas ocorrências, pretendo relacionar o seu funcionamento com a mundividência dos contos torguianos, numa perspectiva qualitativa, que considera e valoriza os papéis dos interlocutores no discurso, a negociação da interacção em curso:

3 Joaquim Fonseca (1992 e 1994) considera esta questão central para o entendimento das novas perspectivas teóricas de abordagem da língua, como linguística do uso/funcionamento do sistema.

4 É uma designação abrangente que inclui a Análise Conversacional, por exemplo.

5 Sobre a necessidade e pertinência de uma linguística dos géneros, ver Maria Antónia Coutinho (2005).

6 Falta, para a língua portuguesa, um estudo sistemático e abrangente das formas de tratamento, do seu uso e funcionamento. No entanto, alguns trabalhos, mais ou menos sectoriais, têm vindo a ser publicados, para além do texto ainda fundamental de Lindley Cintra (1972). Reenviamos, por exemplo, às teses de doutoramento de Carreira (1997), Rodrigues (2003) e aos diversos trabalhos de Oliveira, de que destacamos Oliveira (2005). 
Some of the more interesting elements of language may prove particularly resistant to quantification. Indeed, as Lavandera (1982: 8) argues, a major defect of the quantitative approach is to treat all occurrences of a given variable equally and thus ignore the pragmatic dimension of language in use (Stewart, 2003: 198).

\section{O mundo dos contos torguianos - da relação com a Terra}

É quase um cliché falar da dimensão telúrica da obra torguiana. Mas a verdade é que é o próprio Torga a retomar com frequência o termo e a desenvolver o conceito 7 . Além disso, o mundo de Contos da Montanha ganha forma sobre esta dimensão telúrica do ser humano. Característica essencial de Torga, não é nunca um paraíso perdido e reencontrado. É, antes, uma inteireza, uma proximidade essencial à Terra mãe/mulher criadora, que convoca o antigo mito grego do nascimento dos homens. Tudo daí decorre ${ }^{8}$. Torga apresenta em Contos da Montanha um mundo natural, no sentido de que homens e natureza formam uma unidade. Dela, os homens retiram a sua força. O mundo dos Contos da Montanha é um mundo "terroso", que se alimenta da serra onde os homens criam raízes, uma serra dura, fragosa, que exige esforço, trabalho, ascetismo 9 . Também, por isso, é um mundo rural e fechado, que apenas tolera, como Torga refere em "Portugal", o padre e o médico, ligados pelo locutor numa ironia construída a partir de uma relação associativa indevida, marcada pela

7 Nos Diários (Torga 2007b: 1640): "Portugal telúrico e arcaico ainda não desfigurado na alma (...) do arado e do remo" (Diário, 25 de Setembro de 1988).

8 Por isso, o sentimento telúrico de Torga é mais do que uma respiração serrana: "Figueira da Foz, 8 de Novembro de 1986 - Foi um amor à primeira vista, que ainda dura. O mar que agora contemplo é o mesmo que outrora me deslumbrou. (...). O meu telurismo é oceânico" (Diário XIV, Torga 2007b: 1566); "Oura, 1 de Agosto de 1987 - O mar. Mal cheguei, mergulhei nele. Vinha abrasado de saudades. Os que falam do meu telurismo, nem de longe imaginam o fascínio que sinto pelas ondas. Nasci de facto em terra firme. Mas sou anfíbio, carnal e espiritualmente" (Diário XV, Torga 2007b: 1594).

9 Em "Um Reino Maravilhoso", caracteriza os transmontanos como "Homens de uma só peça, inteiriços, altos, espadaúdos, que olham de frente e têm no rosto as mesmas rugas do chão." (Torga 2007a: 28). São as mesmas qualidades que escolhe para, no prefácio da tradução castelhana dos Contos, indistintamente descrever os contos e as personagens:

"Coimbra, 20 de Março de 1987 - Prefácio à tradução castelhana dos Contos e Novos Contos da Montanha.

\section{QUERIDO LEITOR}

Hesitei muito antes de te escrever esta carta de recomendação. Os interessados não ma pediram, de mais a mais. Heróis altivos, cingidos às leis da condição, desde o nascimento que estão acostumados a enfrentar os caprichos do destino (...). Portugueses, como é evidente, viram a luz do dia nas terras altas de Trás-os- -Montes, província que fica no norte do país. Têm, pois, todos os traços fisionómicos próprios da região. Duros e terrosos" (Torga 2007b: 1572). 
estrutura coordenada do complemento verbal "pregam editais nas portas e sermões nas igrejas", e que secundariza o lugar de ambos neste mundo primeiro:

(0) É ela [a vontade nativa] que, a bem ou a mal, acaba por dispor das riquezas que lhe pertencem: das águas de regadio, dos baldios, da mulher e dos filhos, e de si. De tudo o que na vida material e espiritual tem grandeza e sentido. No pormenor, no que não é seiva de ninguém, dão sentenças o Regedor e o senhor Abade, que, afinal, pregam editais nas portas e sermões nas igrejas...

(Torga 2007a: 24-25)

Mais ainda, a abertura ao mundo exterior impõe renegar estas raízes. Não há pontes a estabelecer, porque, como referi, as personagens tiram a sua força da relação com a terra. E, também, por isso, porque podendo ser geográfica é sobretudo um estado de alma, acontece que por vezes quem vem de fora se torna (da) terra e quem sai a leva intacta na alma, como é o caso do Padre João, do conto "Homens de Vilarinho", ou do Ruela, regressado das aventuras na selva amazónica, de "A Promessa".

A Vila, a cidade -o resto do mundo- são algo de artificial, estranho a essa alma rude, enraizada em fragas, e que neste confronto perde quase sempre a raiz-que também é harmonia- original. Os poucos contactos com o mundo exterior ao espaço da aldeia são reduzidos ao inevitável, ou têm a marca da desgraça. Como o homem de Maria Lionça, no conto com o mesmo nome, e todos os outros "renegados".

Estas características reflectem-se nas interacções pessoais, na forma como as personagens dos Contos da Montanha se relacionam pelo discurso, e de que as formas de tratamento constituem marca relevante. Compreender, assim, o mundo torguiano passa pela análise das relações interpessoais e das formas de tratamento.

\subsection{Os diálogos em Contos da Montanha e a figura do narrador}

O narrador de Contos da Montanha é parte integrante e fundamental do mundo que narra. É personagem, partilha opiniões e sentimentos, revê-se nas grandezas e misérias humanas; como toda a comunidade rural, criou raízes que o tornam um deles. O seu olhar é o de mais um homem ${ }^{10}$ da aldeia, que só entende o seu mundo e assim o expressa:

(1) -Dá licença, senhor padre João?

-Entra, Firmo. Alguma novidade?

-Nada de importância...

$[\ldots]$

$10 \mathrm{O}$ mundo criado por Torga é assumidamente masculino. 
-Bem. Isso é o que eu gosto de ouvir.

[...] o desertor começou a gaguejar:

-Pois é verdade... Afinal...

("Homens de Vilarinho", Torga 1987: 54-55)

(2) -Ninguém me quer, tia Mariana!

E dava uma gargalhada das dela, muito clara, muito pura, pondo à mostra uns dentes que cegavam a gente.

(“Amor", Torga 1987: 38)

De facto, o narrador tem uma presença forte. Toma conta dos diálogos que, diga-se, na economia dos Contos da Montanha ${ }^{11}$ são pouco frequentes. Não são, efectivamente, uma estratégia muito escolhida pelo narrador, contudo, permitem trazer à luz dimensões fundamentais do mundo discursivo ${ }^{12}$. Porque vive nas suas personagens e com elas, os diálogos que reproduz são sistematicamente interrompidos e truncados, numa clara e pretendida conjunção de vozes. Ou seja: o narrador toma conta dos diálogos, compõe uma polifonia onde a sua voz se harmoniza com as vozes das personagens, pelo recurso frequente ao discurso indirecto livre, marcado nos tempos verbais, estruturas oralizantes e expressões de cariz popular:

(3) Naquela noite, depois dum caldo que nem a cães, e de todas as demais hipóteses arredadas, a miragem voltou, mas sem a indecisão das tentações anteriores. Não havia que ver. O sítio não podia ser melhor; à porta, bastavalhe um empurrão; o resto, quêe? Acender uma vela do altar, forçar a fechadura da caixa das esmolas, encher o bolso, e ala morena.

(“O roubo", Torga 1987: 26)

Com frequência, também, o discurso indirecto livre surge entrelaçado com o discurso indirecto, que cria uma perspectiva de zoom que ora distingue ora funde a voz do narrador na voz das personagens:

(4) Cansado de guardar o caminho velho por onde desde que o mundo é mundo se regressa da Vila, pediu à mãe que o deixasse ir esperar o pai. Só até à Castanheira...

Se não via a névoa a cobrir tudo! Se não ouvia as Trindades! Tivesse juizinho.

(“O Cavaquinho", Torga 1987: 60)

11 A partir de agora Contos.

12 Ver Isabel Margarida Duarte (2003) e Laurence Rosier (1999). 


\section{Construção das relações interpessoais em Contos da Montanha}

O estudo da linguagem verbal em uso, desde cedo evidenciou a sua dimensão interaccional, a importância que a relação interpessoal assume na construção do discurso, da comunicação verbal, para além dos tradicionais "conteúdos", ou melhor, numa reformulação teórica que tem vindo a ampliar a importância do "interpessoal", como parte fundamental do conteúdo comunicado ${ }^{13}$ : "Une part importante du matériel produit au cours de l'interaction n'a d'autre fonction que relationnelle." (Kerbrat-Orecchioni 1992: 13).

A esta dimensão da interacção discursiva pertence o sistema das formas de tratamento, que tem merecido, desde o início dos anos 60, e particularmente com Brown e Gilman e Brown e Levinson, nos anos 70 e 80, lugar particular nas investigações que se reclamam de uma perspectiva pragmática ${ }^{14}$.

Segundo Brown e Gilman (1960), o sistema das formas de tratamento ${ }^{15}$ organiza- $^{-}$ se segundo dois eixos: o do TU e o do VÓS, repartidos segundo dois parâmetros: distância ou solidariedade e estatuto ou poder.

Pese embora as críticas às limitações do modelo, que não dá conta da complexidade dos usos, a análise das relações interpessoais desenvolveu-se assente na identificação -e reformulação- destes parâmetros de natureza sociológica que regulam as interacções verbais, a partir das características psicossociais dos interlocutores. Kerbrat-Orecchioni resume esses desenvolvimentos do seguinte $\operatorname{modo}^{16}$ :

Shank \& Abelson (1977:142) synthétisent en quelque sorte les différentes propositions précédentes en proposant les trois dimensions suivantes : intimité vs distance, dominations vs soumission, sentiment positif vs négatif (KerbratOrecchioni 1992: 35).

13 É o desenvolvimento teórico que beneficia da abertura da análise discursiva a outras áreas das ciências humanas e sociais. A pragmática linguística vai integrar, às suas teorizações, a aproximação que faz a outras ciências humanas e sociais, nomeadamente ao interaccionismo simbólico de que Goffman é autor fundamental. A ele se deve (Goffman 1974: 27) a referência à significação ritual do discurso e de alguns enunciados em particular (na sequência de Durkheim), ou seja, na terminologia usada na análise conversacional, o conteúdo relacional do discurso.

14 Ver a súmula apresentada por Kerbrat-Orecchioni (1992).

15 Ver sobre esta questão Kerbrat-Orecchioni (1992: 17).

16 Kerbrat-Orecchioni recupera os parâmetros já discutidos e estabelecidos mas propõe uma alteração terminológica, no que concerne ao terceiro parâmetro, substituindo sentimento positivo vs negativo pelo par conflito/consenso (1992: 36). 
Para um uso teórico-metodológico mais profícuo e adequado, é fundamental considerar que esta classificação não é dicotómica. Por um lado, cada termo do par constitui o pólo máximo de uma gradação; por outro, num mesmo texto, a relação não é estática e, por isso, as duas vertentes de cada correlação podem co-ocorrer, de forma que o que está em causa é a consideração de três eixos inter-relacionados que regulam/identificam três vertentes complementares nas relações interpessoais:

-solidariedade

-poder

-afectividade (relação conflito vs consenso)

O predomínio das duas primeiras vertentes é, segundo Brown e Levinson (1987), critério para determinar, em conjunção com os conceitos também propostos pelos autores de cortesia positiva e cortesia negativa, dois tipos básicos de sociedade, baseados respectivamente na solidariedade, ou melhor, no predomínio do grupo face ao indivíduo, e no privilégio do indivíduo, na distância que a preservação da sua face negativa ${ }^{17}$, ou seja, do seu território, impõe.

\subsection{A organização social nos Contos: uma sociedade solidária}

\subsubsection{O colectivo}

As comunidades representadas nos Contos são, globalmente, sociedades solidárias. Cabe ao narrador acentuar esta dimensão, e fá-lo através da personificação do povoado, representado como uma personagem colectiva, atenta a cada um dos seus indivíduos, e que reage em nome de um equilíbrio, de um sentir e de um ser fundamentais. Vilarinho, Saudel, Guiães e Litém são quatro desses povoados:

\section{(5) E Vilarinho desanimava.}

-Coisa assim, como ele se pôs! E ainda se fosse de gente doutra condição, vá lá com mil demónios! Agora quem lhe conheceu o pai, como um sério zelador do que lhe pertencia, amigo da família, sempre agarrado à enxada...

("Homens de Vilarinho", Torga 1987: 48)

(6) De Cristo, Nosso Senhor, fazia o Coelho, que nem de encomenda para o papel.

-O Coelho?!!! - e Saudel olhou, assombrado, o homem da Joana Perra.

(“A Ressurreição", Torga 1987: 65)

17 Face negativa é o termo proposto por Brown e Levinson (1987) para o que Goffman (1974) designa como território. 
(7) Litém, pela boca do prior, chamou a rapariga à pedra. [...]. Com semelhante conversa, Litém resolveu aguardar.

(“A Paga", Torga 1987: 113)

(8) O frio que sentia na alma tirava a significação a tudo. E Guiães não insistiu. (“Solidão", Torga 1987: 134)

\subsubsection{Nós e os Outros: proximidade, igualdade e hierarquia}

\section{a) Poder e solidariedade}

Mas a complexidade marca necessariamente as relações interpessoais, mesmo em comunidades fechadas e pequenas como as representadas nos Contos.

Não há grandes proprietários ou senhores. Ou, se existem, não fazem parte da vivência colectiva. Apenas têm lugar o médico e o padre, necessários à “cura” da alma e do corpo, e mesmo estes apresentam estatutos particulares, ainda que enquadrados numa relação vertical, assimétrica, que os isola num plano superior, é certo, mas à parte. Esta relação hierárquica está presente nas formas de tratamento deferente que marcam essa relação assimétrica que evidencia o estatuto de poder de um dos interlocutores face ao outro, cruzado, no entanto, e é muito claro na interacção do abade com os seus paroquianos, com uma relação de proximidade, afectiva, paternal, marcada nas formas de tratamento, pelo uso da forma "tu", do nome próprio ou nomes de qualidade e no "conteúdo" da interacção, que, de cariz pessoal, evidencia a implicação afectiva do locutor:

(9) -O teu homem tem-te escrito, Maria? -perguntava o prior pela Páscoa.

-Ele não, senhor. Há quinze anos....

$[\ldots]$

-Nada, Maria? -O prior já nem se atrevia a alargar a pergunta.

$-N a d a$.

("Maria Lionça", Torga 1987: 18)

(10) E sempre que Firmo vinha à terra e acordava da primeira noite dormida com a mulher, lá estava ele à entrada da porta com a sua batina rota e o seu cachaço de cavador.

-Dás licença, Firmo?

- Faça favor de entrar, senhor padre João.

-Então tu não terás juizo, homem de Deus?! Tu não verás que tens aqui um rebanho de filhos?!

$[\ldots]$

("Homens de Vilarinho", Torga 1987: 48) 
A serra é, nos Contos, padrão de conduta, a medida de todas as coisas. Só a ela se tolera a desmesura, o excesso. O resto é «natural» e simples, apenas governado pelo Tempo. E é o Tempo que define uma outra hierarquia, mais fundamental, que também não se opõe à solidariedade. Com efeito, impera a hierarquia do tempo do nascimento. Os mais velhos recebem dos mais novos tratamento de $3^{\text {a }}$ pessoa, os mais novos recebem dos mais velhos tratamento de $2^{\mathrm{a}}$ pessoa (tu):

(11) -Deixe correr que ainda bota, ti Violante. Uma carta custa apenas o selo e o papel.

-Parece-te! Pode custar muita lágrima. Não estiques a corda demais...

(“Amor", Torga 1987: 40)

(12) -Que diz, minha mãe: mando-lhe pôr uma vareta no guarda-sol? -Manda.

(“A Revelação”, Torga 1987: 192)

O pronome "você", sem o valor pejorativo que assume noutros contextos interaccionais na comunidade linguística portuguesa actual, constitui uma das formas usuais de marcação dessa assimetria geracional:

(13) -Você que tem, ti Joana? Anda tão desolhada!...

-Nem sei. Dores no corpo, sem nenhuma vontade de comer,

("Bruxedo", Torga 1987: 104)

Mas, para um mesmo tempo de vida, uma mesma geração, há um mesmo e único tratamento de simetria, mostrado no uso de 'tu':

(14) -Com que então desta vez sempre ficas por cá?! -foi perguntando o Puga, pela mansa, quando encontrou o Firmo a jeito.

-É como dizes. O bom filho à casa torna...

("Homens de Vilarinho", Torga 1987: 52)

O próprio narrador participa desta simplicidade de relacionamento interpessoal. As personagens só têm nome próprio: o Faustino, a Maria Lionça, a Cacilda, o Firmo... É ainda pelo narrador que temos conhecimento das alcunhas que, como segundo baptismo, agora de natureza popular mas acutilante, acompanham as personagens:

(15) A Melra fora sempre como aço. A ter os filhos, era um ai que lhe dava; ("Bruxedo", Torga 1987: 104) 
A solidariedade, por sua vez, alimenta a comunidade, mas é feita de frugalidade, de contenção ${ }^{18}$. Frugalidade da terra e das gentes, frugalidade e contenção na comunicação. A relação de intimidade não é explicitamente marcada no discurso por formas de tratamento particulares. O uso do nome próprio basta para marcar a familiaridade e proximidade da relação:

(16) -Nem há riqueza como a nossa, ó Júlia!

(“Um Filho", Torga 1987: 80)

(17) O filho, Pedro, é que não resistiu ao desencanto. Envergonhado [...] partiu para Lisboa, sem Galafura saber a quê. E nova via-sacra começou na loja do correio.

-Não tens nada, Maria.

("Maria Lionça", Torga 1987: 21)

Ganha, ainda, matizes fundamentais a relação homem - mulher. De facto, mais do que o nome de baptismo que as individualiza, as personagens dos Contos são seres humanos que interagem e partilham a vida. Por isso, "Homem", "mulher", "rapariga"19, "rapaz" são os nomes de tratamento usuais, porque é essa a condição de todos e cada um. Aí reside a forma primeira de igualdade, de solidariedade essencial, que inclui a relação matrimonial (19 e 20):

(18) -Vai-me buscar alguém, homem! Vai-me buscar alguém...

Vai-me buscar alguém...

("Um Filho", Torga 1987: 76)

(19) -Sossega, mulher, sossega! Valha-me Nossa Senhora!

("O Bruxedo", Torga 1987: 108)

(20) -Valha-te Deus, homem! E agora?

(Vindima, Torga 1987: 174)

(21) -Tu que tens, mulher?

-Dói-me a cabeça ...

-Faz uma pinga de chá.

(“A Revelação", Torga 1987: 194)

(22) -Arranja-te, rapariga! Ou queres ficar aí pasmada toda a vida?

(“A Revelação", Torga 1987: 194)

18 Ver Haverkate (2004), sobre as características de uma sociedade solidária.

19 Ou a sua variante popular "cachopa" (cf. exemplo 26). 
(23) -Não fervas em pouca água, rapaz! O primeiro demora sempre muito.

Só lá para amanhã... Anda-me chamar, então.

("Um Filho", Torga 1987: 78)

Se, em termos de hierarquia, a precedência na vida -ser mais velho- marca a relação interpessoal, as formas de tratamento nos Contos sobrepõem, contudo, uma dinâmica de solidariedade a esta dinâmica de poder. $\mathrm{O}$ uso de termos de parentesco como forma de tratamento é sinal dessa relação: "Tio/Tia" são usados para marcar a hierarquia (do tempo, ou seja, geracional), mas simultaneamente, e sobretudo, marcam a solidariedade:

(24) -Grandes terras, ti Guilhermino!

Não há dúvida, Firmo... Não há dúvida... Os lucros que tens tirado dela é que são fracos.

("Homens de Vilarinho", Torga 1987: 48)

(25) Ao menos tem pena deles, cachopa. Manda pôr uma braseira debaixo do negrilho e outra no cruzeiro...

-Eles não têm frio. Quanto mais, deixe falar, tia Cláudia! Se andam de noite, lá andam à sua vida. Cá comigo não há nada. Querem coisa mais alta.

(“Amor", Torga 1987: 40)

Mas a solidariedade não se reduz ao núcleo do povoado. Existe um sentido de irmandade que se estende aos desconhecidos, sentidos como da mesma condição humana. O uso do termo de parentesco "tio" reforça esse valor universal e solidário, na conjunção com o nome "homem":

(26) -Oiça lá, tio homem, componha-me aqui isto.

-De mil amores.

-Não é preciso tanto. Basta que seja bem.

$[\ldots]$

-Deixe cá ver...

(“A Revelação”, Torga 1987: 192)

(27) -Ó tio homem!

-menina...

-Espere aí, se faz favor.

- espero, sim senhora.

(“A Revelação”, Torga 1987: 199) 
No entanto, a deferência imposta pela relação distante, pela ausência de intimidade, faz aparecer outras formas de tratamento, inexistentes nas relações intra-grupo, marcando uma relação formal e simétrica:

(28) -Costuma-se dizer que favores de gente honrada não se enjeitam. Mas contas são contas. Ande lá, e deixe-se de brincadeiras.

-Já lhe disse.

-Mau!

-Não seja soberba, menina! Ou é por causa da insignificância? Para outra vez será coisa melhor...

(“A Revelação”, Torga 1987: 192-193)

(29) -Ora prontinho. Aqui tem.

-Quanto lhe devo?

-Está pago.

-Pago por quem?

-Eu cá me entendo ... Adeus, menina. Muita sorte é o que lhe desejo.

(“A Revelação", Torga 1987: 199)

O papel social dos interlocutores (mãe e filha; comprador e vendedor) e a necessidade de mitigar um acto ameaçador (FTA) merecem particular atenção. É por isso que a forma "vossemecê(s)" é retomada, apesar de já estar substituída nas relações 'habituais' do quotidiano da aldeia pela forma abreviada "você". É que "vossemecê", apesar de quase em desuso, conserva, ainda e ao contrário da nova forma 'você', um prestígio que assegura o êxito destes funcionamentos, ao serviço de uma intenção persuasiva, que enfatiza a relação fundamental de respeito em situação de desacordo:

(30) - A catorze.

-Olha a catorze! Vossemecês endoideceram ...

("Solidão", Torga 1987: 127)

(31) - A como quer por ele?

$-A$ dezasseis.

- A dezasseis! Vossemecês não estão bons da cabeça...

("Solidão", Torga 1987: 128-129)

(32) - Afinal, o Artur veio falar comigo ... -começou a mãe, numa tarde de monda.

-Quer casar com vossemecê?

-Parece tola! Contigo, mulher!

(“A Revelação", Torga 1987: 196) 


\section{b) Consenso e conflito}

Consideremos, finalmente, o terceiro eixo regulador das relações interpessoais para centrarmos a atenção no pólo do conflito, que constitui uma vertente importante das relações humanas representadas. É que neste mundo rude não há lugar para refinamentos de linguagem: quando o conflito rebenta, vem eivado do "chão raivoso" 20 , da terra dura, fragosa e bravia da serra que só por porfia dos homens se abre ao cultivo. As formas de tratamento servem, também, à marcação desta dimensão, com especial destaque para os insultos, reforçados por violentas pragas, e marcados no uso de nomes de qualidade disfóricos de claro valor axiológico:

(33) A Inês, a viúva do Ruela [...] foi ter com o Lucas:

-Ouviu? Se você me faz pantominas à porta no dia da morte do meu homem, eu até a alma lhe como, seu galhudo!

(“A Promessa", Torga 1987: 86)

(34) -Por vergonha é que o não ponho daqui para fora a pontapés. Na mortalha do meu homem fazer-me esta pouca vergonha à porta! Seu badana! Seu grande corno!

$[\ldots]$

A Inês, desvairada, nem o ouviu:

-Consumido seja você nas profundas dos infernos e mais a puta que o enfeita.

$[\ldots]$

(“A Promessa”, Torga 1987: 93-94)

(35) -Farto seja você de tribunais nas profundas dos infernos! Não tem olhos na cara? Não vê que isto é meu, seu ladrão?!

("Justiça", Torga 1987: 162)

Mas o alocutário dos Contos não é apenas o indivíduo singular, que até agora tem vindo a ser analisado. Sem o relevo discursivo que este assume, o alocutário plural tem, no entanto, o seu lugar na definição e identificação de grupos diversificados.

É particularmente saliente a representação no discurso de um alocutário plural que se afirma como uma forma de marcar duas sociedades, distintas e opostas, primeiramente determinadas a partir do espaço geográfico. Com efeito, para o espaço rural da aldeia, é privilegiado o uso tradicional de vós. Tem essa primeira função de marcador espacial-temporal-social por oposição ao "moderno" vocês, com idêntica função deíctica espacial-temporal-social, quando usado "pelos da Vila".

20 A expressão é de Torga, em Portugal, no capítulo "Um reino maravilhoso": «Léguas e léguas de chão raivoso, contorcido, queimado por um sol de fogo ou por um frio de neve" (Torga 2007a: 25). 
Cumulativamente, esta divergência de formas de tratamento marca a independência dos primeiros face aos segundos, habitantes de mundos separados, com valores opostos:

(36) -Muito bem. Ide-vos, então, rapazes. E descansai. Quem paga é aqui o nosso milionário.

(“Justiça", Torga 1987: 166)

(37) -Cá por mim não a trago nem com açúcar!

-Hás-de ver que vos dais bem.

("Um coração desassossegado", Torga 1987: 181)

(38) E foi nessa altura que o Anelhe teve uma inspiração.

-Suspendei lá isso. Fazei de conta que ele não morreu por enquanto.

(“O Pé Tolo", Torga 1987: 224)

(39) Apenas o conservador do Registo Civil, mais papista que o Papa, se aproximou do Anelhe e o interpelou:

Vocês não tinham em Bravães ninguém mais decente para mandar?

(“O Pé Tolo”, Torga 1987: 224)

Com efeito, a relação com a Vila, isto é, com o exterior, é difícil pelas razões acima apontadas. Mas existe porque é necessária. Com "os da Vila”, a exterioridade é sempre marcada nas formas de tratamento. É de salientar a existência de uma funcionalização da relação interaccional, que decorre de papéis sociais e institucionais que os habitantes da aldeia e da vila são obrigados a assumir (juiz/réu; chefe de repartição/contribuinte; médico/paciente). Como consequência, impõem um tratamento distante, formal, assimétrico:

(40) De resto, [o Faustino] não se sentia já com forças para repetir a façanha de Freixoedo. Cinco costelas partidas [...] com o aviso solene do juiz:

-Dou-lhe apenas quatro meses, atendendo a que já foi bem convidado e que é esta a primeira vez que aqui me aparece. Mas não volte! De contrário, perca o amor à liberdade.

("Um roubo", Torga 1987: 26)

(41) -Vocês não tinham em Bravães ninguém mais decente para mandar?

$[\ldots]$

-Não, senhor. Para estes serviços, sou sempre eu.

$[\ldots]$

No outro dia, à entrada da repartição [...]

-António da Silva Osório, diz você? - estranhou o Dr. Acúrcio. 
$[\ldots]$

-Essa agora! Eu vi-o ontem na sessão! Até lhe falei.

-Pois viu, viu! [...]

("O Pé Tolo", Torga 1987: 225)

(42) -Tenha paciência, doutor, e venha-me ver a patroa. Aquilo parece que está ruim ...

(“O castigo", Torga 1987: 207)

(43) -Estou numa cruz, senhor doutor!

$[\ldots]$

-Que exagero! Uma coisa que não presta para nada! Valha Nossa Senhora. Daqui a pouco passa tudo e já nem se lembra.

("O castigo", Torga 1987: 209)

Do mesmo modo, os emigrantes -"brasileiros"- que se estrangeiraram se distinguem pelas formas de tratamento. Não são mais gente da terra, porque em algum momento se afastaram e não conseguiram manter a integridade "original". Em "Maria Lionça", a forma de tratamento, caracteristicamente brasileira mas tão estranha na relação entre pais e filhos da comunidade transmontana, condensa esse afastamento:

(44) O pai pareceu-lhe uma sombra esbatida da imagem recortada que sonhara.

-Seu moço, está mesmo um homem!

("Maria Lionça", Torga 1987: 19-20)

\section{Conclusão}

Ainda que sem pretensão de exaustividade, fica clara a importância da análise das relações interpessoais das personagens (neste caso só a partir das formas de tratamento nos diálogos) para compreender o mundo narrado por Torga. Esta assunção interliga-se com a importância dos funcionamentos e usos de estruturas linguísticas para compreender o discurso (literário) e alarga-se no que permite de compreensão do mundo do quotidiano, o "mundo real". Acresce ainda que as formas de tratamento constituem a categoria discursiva que de forma mais explícita reflecte a estrutura social, enquanto participam na construção de uma identidade social. Por isso, a análise e conhecimento de uma comunidade, do seu funcionamento, das suas estruturas, dos seus valores, seja ou não uma comunidade ficcional, passa pela compreensão das relações interpessoais. Os Contos de Torga, pelas relações de similaridade que estabelecem com as comunidades transmontanas, são um claro 
exemplum do uso das formas de tratamento, do relacionamento interpessoal nessas comunidades rurais transmontanas de meados do século XX.

Determinámos algumas características fundamentais que sintetizamos, agora:

Em Contos da Montanha, estamos perante sociedades globalmente solidárias, daí a importância do colectivo, pela personificação do povoado. As relações verticais, hierárquicas, existem também mas decorrem unicamente do "Tempo", isto é, são geracionais. Por isso, são marcadas em termos de parentesco: pais e, genericamente, “tios". Dentro da mesma geração, a relação é marcada pelo uso recíproco de $t u$, a única forma de tratamento possível quer se trate de amigos ou inimigos, amantes ou irmãos.

Umas e outras são formas de tratamento que marcam uma solidariedade básica, essencial, que se estende, com valores óbvios de deferência que decorrem da ausência de intimidade, a personagens que, sendo desconhecidas, partilham a vida, os valores, a terra. Como família "humana", isto é, universal, os seus membros individualizam-se como homens e mulheres, raparigas e rapazes. E assim são tratados. As formas de tratamento dão conta de um espírito gregário que ultrapassa a fronteira estrita do povoado. É um sentido forte de comunidade, em que o grupo se sobrepõe ao indivíduo. Daí resulta uma diminuição do "território" individual, quase anulado pelo "território" comunitário.

São ainda as formas de tratamento a estruturar as relações com o mundo exterior, dando nova dimensão ao valor espacial-temporal-social que cada uso sistemático foi adquirindo.

Em suma, a dimensão telúrica dos Contos da Montanha, entendida por Torga como "ligação à terra, às tradições, às origens" (3 de Abril de 1983, Diário XIV, Torga $2007 b$ ) é discursivamente marcada por este jogo de formas de tratamento.

\section{Referências bibliográficas}

Brown, R. / Gilman, A. (1960): “The Pronouns of Power and Solidarity”, en Sebeok, T. (ed.), Style in Language: 253-277 (Cambridge, MA: MIT Press).

Brown, P. / Levinson, S. (1987): Politeness - some universals in language usage (Cambridge: Cambridge University Press).

Carreira, M. H. (1997): Modalisation Linguistique en situation d'interlocution. Proxémique et modalités en Portugais (Paris: Ed. Peeters).

Cintra, L. (1986 21 ) [1972]: Sobre as “Formas de Tratamento” na Lingua Portuguesa (Lisboa: Livros Horizonte). 
Coutinho, M. A. (2005): "Para uma linguística dos géneros de texto", Diacrítica 19.1: 73-88.

Duarte, I. M. (2003): O relato de discurso na ficção narrativa: contributos para uma análise da construção polifónica de Os Maias de Eça de Queirós (Lisboa: Fundação Calouste Gulbenkian / Fund. para a Ciência e a Tecnologia).

Fonseca, J. (1992): Linguística e texto/discurso: teoria, descrição, aplicação (Lisboa: Inst. de Cultura e Língua Portuguesa).

Fonseca, J. (1994): Pragmática Linguística - Introdução, teoria e descrição do Português. (Série Linguística, $\left.\mathrm{n}^{\circ} 5\right)$. (Porto: Porto Editora).

Goffman, E. (1974): Les rites d'interaction (Paris: Seuil).

Haverkate, H. (2004): "El análisis de la cortesía comunicativa: categorización pragmalingüística de la cultura española", en Bravo, D. / Briz, A. (orgs.): Pragmática sociocultural: estudios sobre el discurso de cortesía en español: 55-66 (Madrid: Ariel Lingüística).

Kerbrat-Orecchioni, C. (1992): Les Interactions verbales (Paris : Armand Colin).

Oliveira, S. M. (2005): “A retrospective on address in Portugal (1982-2002): Rethinking power and solidarity", en Mosegaard Hansen, M. / Rossari, C. (eds.), The Evolution of Pragmatic Markers. Special issue of Journal of Historical Pragmatics 6:2: 307-323.

Parkinson, D. B. (1985): Constructing a Social Context of Communication. Terms of Address in Egyptian Arabic (Amsterdam: Mouton de Gruyter).

Rodrigues, D. (2003): Cortesia Linguística: uma competência discursivo-textual. Tese de doutoramento (Lisboa: Universidade Nova de Lisboa).

Rosier, L. (1999) : Le discours rapporté: histoire, théories, pratiques (Paris / Louvain-la-Neuve: Duculot).

Stewart, M. (2003): “'Pragmatic weight' and face: pronominal presence and the case of the Spanish second person singular subject pronoun tú", Journal of Pragmatics, 35: 191-206.

Torga, M. (198777): Contos da Montanha (Coimbra: Edição de autor).

Torga, M. (2007a) [1950]: Portugal ( Lisboa: Herdeiros de Miguel Torga e Publicações D. Quixote).

Torga, M. (2007b): Diários. Vol. II (Lisboa: Herdeiros de Miguel Torga e Publicações D. Quixote). 